\title{
The Challenges and Opportunities for the Green Climate Fund
}

\author{
CHEN Lan \\ Foreign Economic Cooperation Office \\ Ministry of Ecology and Environment of China \\ 5 Houyingfang Hutong, Xicheng District, Beijing 100083, China \\ 18601041789@163.com
}

\begin{abstract}
The importance of the public finance in tackling climate change has been widely recognized by the global communities. As the operating entity of the financial mechanism of the UNFCCC and the Paris Agreement, the $\$ 10.3$ billion Green Climate Fund (GCF) holds a potential to be the champion in the international climate finance architecture. Within two and a half years, the GCF approved 76 projects worthy of $\$ 3.7$ billion and has established partnership with 59 accredited entities. Integrating different concerns into its governance and operational modalities, the GCF maintains an inclusive participation and has profound implication for the international climate change cooperation. While with these achievements, the GCF still faces financial and policy challenges going forward. If the current pace of the project approval continues, the GCF will soon exhaust its resource. The existing policy gaps will also jeopardize GCF meeting its climate goals. To ensure a sustainable and bright future, the GCF needs to take advantage of its opportunities and address the challenges in a wise and strategic way. Given the real scarcity of the public resources available, a top-down combined with bottom-up replenishment modality may be worth exploring.
\end{abstract}

Keywords: Paris Agreement; GCF; public climate finance; paradigm shift.

\section{Introduction}

The Green Climate Fund (GCF), established in 2010 at the UN Climate Change Conference in Cancun, serves as an operating entity of the financial mechanism of the UNFCCC and the later adopted Paris Agreement. The fund is intended to promote the paradigm shift toward low-emission and climate-resilient development pathways by providing support to developing countries. As of May 2018, the GCF has raised $\$ 10.3$ billion equivalent in pledges from 43 state governments for its initial resources mobilization (GCF, 2018), which was launched in 2014 and expected to last until 2018. On the eve of the 2015 Paris Climate Summit, the GCF approved its first landmark eight projects worth \$168 million.

After eight years of development, the GCF has fledged into a key institution for global climate finance. The Fund has so far approved 76 projects which will avoid 1.3 billion metric tonners of carbon dioxide emissions while increasing the resilience of 217 million people to climate impact (GCF, 2018). Through its 59 accredited entities, the GCF has established a close partnership with stakeholders to tackle climate changes. ${ }^{1}$ Unlike the

\footnotetext{
${ }^{1}$ The number of accredited entities of the GEF and CIF is 18 and 8, respectively.
} 
Climate Investment Funds (CIF), Global Environment Facility (GEF) and other multilateral climate financial institutions, the GCF has a deep imprint on the democratization of international relations in terms of its governance and institutional arrangements. It has adopted the principles of "consensus" and "accountable to the COP" on its decisionmaking mechanism (GCF, 2011). The equal composition of the Board means that the developing countries have the same voices as developed countries for the Fund decisions. In order to address the funding shortage in adaptation, the GCF aims for a 50:50 funding balance between adaptation and mitigation. Based on the experience of CIF, the GCF established a dedicated Private Sector Facility and a Private Sector Advisory Group to actively engage with the private sectors.

\section{Challenges for the Governance and Operation of GCF}

The governance and operation of the GCF need to integrate interests of different countries. Developed countries want to see the GCF "accelerate the deployment of resources to support high impact, transformational projects, including to catalyze private finance." While on the other hand, developing countries consider the GCF as a manifestation of the principle of "common but differentiated responsibilities," a moral debt repaid by developed countries. The cognitive conflicts rooted in the GCF have negatively affected its efficiency and effectiveness. In order to realize its role in mobilizing finance to pursue low-carbon development and increase climate resilience, the GCF needs to address the following challenges.

\subsection{The prediction and sustainability of the resources}

Although \$10.3 billion has been pledged in initial resources mobilization (2015-2018), the current available resource is only $\$ 7$ billion (World Bank, 2018), which is largely due to US failure to fulfill its commitment. Back in 2014, Obama pledged $\$ 3$ billion to the Fund, while only materialized $\$ 1$ billion before the end of his term. The Trump administration zeroing out contribution to the GCF (confirmed by the congress in the final US FY2018 budget) will greatly increase the burden of other donors. Considering recent pledges of $\$ 4$ billion on GEF-7 and the resources which are diverted to address other immediate needs, the contributing governments' budgets for climate aid are expected to be under pressure. According to the Board decision, once $60 \%$ of contributions have been approved toward projects and programs, the Fund will rely on a systematic process to replenish the resources. Yet almost half of 2018 has passed, the policies and procedures for the formal replenishment process have not been in place, amplifying concerns about the Fund's sustainable development.

\footnotetext{
${ }^{2}$ Australia, the UK and other developed countries produced the "Climate Finance Roadmap to US\$100 Billion," which was released in October 2016, and available at http://dfat.gov.au/international-relations/themes/climatechange/Pages/climate-finance-roadmap-to-us100-billion.aspx.
} 


\subsection{Investment direction of the Fund}

It has been reaffirmed by developed countries that a track record of high-quality programming will help prepare the ground for further replenishments. According to developed countries, the "qualified" project should take into consideration of development, economic and security benefits. For example, the reason that GEF continues receiving support from US government is largely because it has bipartisan roots in the US Congress. And the critical reason behind this is that GEF supports US businesses that provide clean energy and environmental services; 127 US companies, universities and NGOs in 29 states have won contracts to implement GEF projects (Martinez-Diaz and Thwaites, 2018). In contrast, the approved GCF projects have an average co-financing ratio of 1:2.4, comparing 1:9.7 and 1:9.5 with $\mathrm{GEF}^{3}$ and Clean Technology Fund, respectively.

\subsection{Policy gaps and the selection of permanent trustee}

Currently, policy gaps in investment criteria, risk management and accreditation framework greatly disable GCF's operation effectiveness. The uncertainties are creating doubts within stakeholders regarding the prioritization of project proposals, the elaboration of country program or whether there will be a ceiling on the number of accredited agencies. The lack of clarity is also delaying the cooperation between the Fund and the private sectors. On the other hand, the permanent trustee, the critical role of the Fund, has not been selected yet. As a result of compromise between the two groups, the World Bank currently serves as interim trustee for the Fund. The board should select, as soon as possible, an institution that can be trusted to manage the financial assets of the Fund according to the international accepted fiduciary standards. And this process seems to be a part of political games in the board room.

\subsection{Capability of the Secretariat}

The GCF is based in the new Songdo district of Incheon, South Korea, which results in a little difficult for the Fund to attract competitive employees. Although GCF has around 172 staff members today, its senior staff has a relatively high mobility. This limits the capability of the secretariat and somewhat reduces the efficiency of the Fund. The secretariat needs to realize its full potential to act as a bridge among board members to ensure that the Fund operates efficiently. The good news is that the Korea Government attaches a great importance to the GCF. The Fund can enjoy this privilege in its development.

\section{Opportunities for the Development of GCF}

The importance of the public finance in tackling climate change has been widely recognized by the global communities. Several climate funds have been established to incentivize private investors to shift their capital toward sustainable initiatives (Amerasinghe et al.,

\footnotetext{
${ }^{3}$ Climate change focal area only.
} 
2016). As the latest and largest climate fund, the GCF holds a great potential to advance climate objective.

\subsection{GCF holds an extensive international political consensus}

The history of the GCF can date back to 2009 Copenhagen Climate Summit. The final establishment of the fund, mustering on political consensus, demonstrates the international community's determination to work together to address climate change. Although it is a newcomer in the climate finance landscape, the GCF is expected to be a key channel for achieving not just $\$ 100$ billion, but supporting the broader implementation and transformational goals of the Paris Agreement. Compared with other multilateral funds, the GCF has a more inclusive participation. As an essential indicator for climate cooperation in climate change, the successful operationalization of the GCF in 2015 injected political impetus into the Paris Climate Change Summit. The successive climate talks also need GCF to boost cooperation.

\subsection{The alternative/non-governmental sources can be explored}

The GCF has a flexible financial inputs mechanism. Except the contribution from governments, the Fund also receives funds from a variety of other sources. The initial resource mobilization period accepts new pledges on an ongoing basis. Although Trump administration withdrew its support from the GCF, the momentum to fight against the climate change remains. States, cities, philanthropists and other actors can still step in to fill the vacuum. For example, the GCF can explore a way to cooperate with the proposed America's Climate Fund (Martinez-Diaz and Thwaites, 2017) and other emerging climate funds. Also, the range of financial instruments and the delicate private sector facility make the GCF hold the potential to further mobilize multiple stakeholders.

\subsection{The Board is taking actions to round off the gaps}

To fill the policy gaps, the GCF needs to struggle to keep a balance between developed countries' business interests and developing countries' climate needs. Holistic and clear policies through which the Fund can make a difference are to be considered in the context of the imperative to ensure that the Fund's investments respond to country circumstances, needs and priorities, as well as practical considerations such as accredited entities' capacity and ability to deliver. The good news is that the decision-makers have recognized the problems and they are now endeavoring to seek the sweet spots between developed and developing countries in the boardroom.

\subsection{The architecture of the multilateral climate finance is evolving}

Among existing multilateral climate funds, there are some overlapping of roles and duplication of efforts. Policymakers are now raising questions about how to improve coherence and complementarity and respond to developing countries' needs in order to 
enhance effectiveness (Amerasinghe et al., 2016). The Special Climate Change Fund, the Least Developed Climate Fund, and the Adaptation Fund are facing resources constraints and the last is struggling to be conferred legal status under Paris Agreement. The GEF-7 replenishment cuts its support for climate change focal area by more than one-third. The CIF, existing outside of the UNFCCC framework, conceives a sunset clause which requires it to conclude its operations once a new financial architecture is effective. At present, the GCF can enhance cooperation with other climate funds and absorb wisdom and best practices from its counterparts. In a longer term, some funds might be consolidated or sunset.

With the latest approval of over $\$ 1$ billion project package, the GCF portfolio amounts to $\$ 3.7$ billion. The Fund is now poised to deliver even greater result in assisting the economies on the right path. However, assuming the Board continues to approve funding proposals at this rate, GCF's initial resources will soon be exhausted. Based on the experience of Paris Agreement, combining a top-down and bottom-up modality may be a realistic way to ensure the success of the coming resource infusion. To kick off, the GCF needs to act wisely to fill policy gaps, demonstrate its unique niche in the landscape of the climate finance, and adopt an innovative strategy to attract not only government contributors but also non-governmental resources, such as philanthropic actors, private and public pension funds, insurance, and other institutional investors. And of course, the political mutual trust among the board members is a prerequisite for the success of the above-mentioned process.

\section{References}

Amerasinghe, Niranjali, Joe Thwaites, Gaia Larsen, and Athena Ballesteros. 2016. The Future of the Funds. Washington: World Resources Institute. https://www.wri.org/sites/default/files/ The_Future_of_the_Funds_0.pdf (accessed February 25, 2018).

Green Climate Fund (GCF). 2011. "Governing Instrument for the Green Climate Fund." https:// www.greenclimate.fund/documents/20182/56440/Governing_Instrument.pdf/caa6ce45-cd544ab0-9e37-fb637a9c6235 (accessed April 20, 2018).

Green Climate Fund (GCF). 2018 “GCF PORTFOLIO.” https://www.greenclimate.fund/what-wedo/portfolio-dashboard (accessed May 29, 2018).

Martinez-Diaz, Leonardo, and Joe Thwaites. 2017. "How the United States Can Remain Engaged in International Climate Finance." http://www.wri.org/blog/2017/12/how-united-states-canremain-engaged-international-climate-finance (accessed December 11, 2017).

Martinez-Diaz, Leonardo, and Joe Thwaites. 2018. "A Key Week for the Future of the Global Environment Facility as Countries Re-up Its Funding.” http://www.wri.org/blog/2018/ 04/key-week-future-global-environment-facility-countries-re-its-funding (accessed April 24, 2018).

World Bank. 2018. "Green Climate Fund (GCF)." http://fiftrustee.worldbank.org/Pages/gcf.aspx (accessed June 3, 2018). 